\title{
Uranium dioxides and debris fragments released to the environment with cesium-rich microparticles from the Fukushima Daiichi Nuclear Power Plant
}

DOI:

10.1021/acs.est.7b06309

\section{Document Version \\ Accepted author manuscript}

Link to publication record in Manchester Research Explorer

Citation for published version (APA):

Ochiai, A., Imoto, J., Suetake, M., Komiya, T., Furuki, G., Ikehara, R., Yamasaki, S., Law, G., Ohnuki, T., Grambow, B., Ewing, R. C., \& Utsunomiya, S. (2018). Uranium dioxides and debris fragments released to the environment with cesium-rich microparticles from the Fukushima Daiichi Nuclear Power Plant. Environmental Science and Technology. https://doi.org/10.1021/acs.est.7b06309

\section{Published in:}

Environmental Science and Technology

\section{Citing this paper}

Please note that where the full-text provided on Manchester Research Explorer is the Author Accepted Manuscript or Proof version this may differ from the final Published version. If citing, it is advised that you check and use the publisher's definitive version.

\section{General rights}

Copyright and moral rights for the publications made accessible in the Research Explorer are retained by the authors and/or other copyright owners and it is a condition of accessing publications that users recognise and abide by the legal requirements associated with these rights.

\section{Takedown policy}

If you believe that this document breaches copyright please refer to the University of Manchester's Takedown Procedures [http://man.ac.uk/04Y6Bo] or contact uml.scholarlycommunications@manchester.ac.uk providing relevant details, so we can investigate your claim.

\section{OPEN ACCESS}


1 Uranium dioxides and debris fragments released to the environment with cesium-rich microparticles

5 Ikehara, ${ }^{1}$ Shinya Yamasaki, ${ }^{2}$ Gareth T. W. Law, ${ }^{3}$ Toshihiko Ohnuki,${ }^{4}$ Bernd Grambow, ${ }^{5}$ Rodney

$9 \quad{ }^{2}$ Faculty of Pure and Applied Sciences and Center for Research in Isotopes and Environmental Dynamics, University of Tsukuba, 1-1-1 Tennodai, Tsukuba, Ibaraki 305-8577, Japan

$11{ }^{3}$ Centre for Radiochemistry Research, School of Chemistry, The University of Manchester, Oxford Road, Manchester, M13 9PL UK

$13{ }^{4}$ Laboratory for Advanced Nuclear Energy, Institute of Innovative Research, Tokyo Institute of Technology, 2-12-1 Ookayama, Meguro-ku, Tokyo 152-8550, Japan 
${ }^{6}$ Department of Geological Sciences and Center for International Security and Cooperation,

19 Abstract

20 Trace U was released from the Fukushima Daiichi Nuclear Power Plant (FDNPP) during the

21 meltdowns, but the speciation of the released components of the nuclear fuel remains unknown.

22 We report, for the first time, the atomic-scale characteristics of nano-fragments of the nuclear

23 fuels that were released from the FDNPP into the environment. Nano-fragments of an intrinsic

24 U-phase were discovered to be closely associated with radioactive cesium-rich microparticles

25 (CsMPs) in paddy soils collected $\sim 4 \mathrm{~km}$ from the FDNPP. The nano-scale fuel fragments were

26 either encapsulated by or attached to the CsMPs and occurred in two different forms: $(i) \mathrm{UO}_{2+\mathrm{x}}$

27 nanocrystals of $\sim 70 \mathrm{~nm}$ size, which are embedded into magnetite associated with Tc and Mo on

28 the surface. (ii) Isometric (U,Zr) $\mathrm{O}_{2+\mathrm{X}}$ nanocrystals of $\sim 200 \mathrm{~nm}$ size, with the $\mathrm{U} /(\mathrm{U}+\mathrm{Zr}$ ) molar

29 ratio ranging from 0.14 to 0.91 , with intrinsic pores $(\sim 6 \mathrm{~nm})$, indicating the entrapment of vapors

30 or fission-product gasses during crystallization. These results document the heterogeneous

31 physical and chemical properties of debris at the nanoscale, which is a mixture of melted fuel

32 and reactor materials, reflecting the complex thermal processes within the FDNPP reactor during

33 meltdown. Still the CsMPs are an important medium for the transport of debris fragments into

34 the environment in a respirable form. 

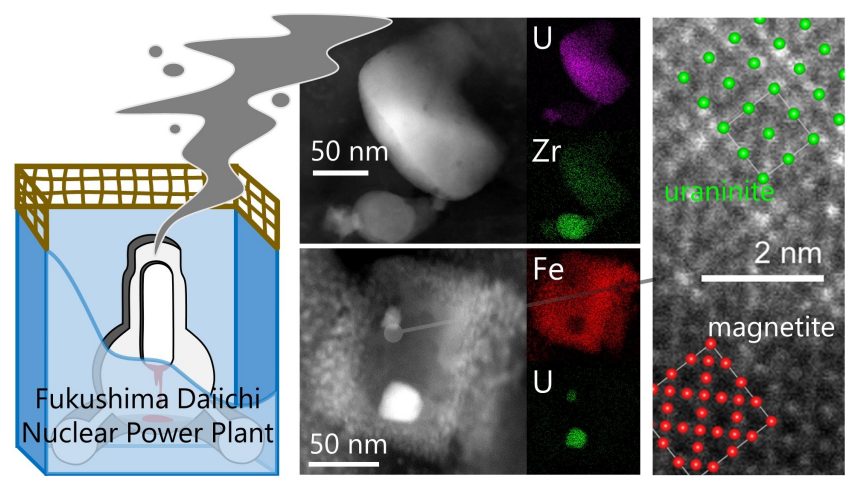

Introduction

38 The nuclear disaster at the Fukushima Daiichi Nuclear Power Plant (FDNPP) in March 2011

39 released $\sim 5.2 \times 10^{17}$ becquerels $(\mathrm{Bq})$ of fission products and actinides into the environment. ${ }^{1}$ At

40 present, the principal contributions to radiation dose in the surrounding environment are derived

41 from ${ }^{134} \mathrm{Cs}$ and ${ }^{137} \mathrm{Cs}$ because of their half-lives (2.065 and 30.17 years, respectively), their high

42 mobility in the atmospheric environment, and the large released activity $\left(\sim 10^{16} \mathrm{~Bq}\right.$ of ${ }^{134} \mathrm{Cs}$ and

$\left.43{ }^{137} \mathrm{Cs}\right) \cdot{ }^{1,2}$ Although soluble species such as $\mathrm{CsOH}$ and CsI are typically reported as Cs phases in

44 the severe accidents with irradiated fuels, ${ }^{3}$ sparingly soluble Cs-rich micro-particles (CsMPs)

45 that mainly comprise Si-glass and Fe-Zn-Cs nanoparticles have been recently identified as an

46 unexpected chemical form of Cs released from the FDNPP. ${ }^{4,5}$ The CsMPs are considered to form

47 through the condensation of $\mathrm{SiO}(\mathrm{g})$ vaporized through molten corium-concrete interaction

48 (MCCI), in which the melted nuclear fuel abruptly reacts with the concrete pedestal of the

49 nuclear reactor primary-containment vessel (PCV). ${ }^{5,6}$

50 The CsMPs have been occasionally found associated with trace U. ${ }^{7,8}$ Further detailed

51 characterization revealed that in some cases the $\mathrm{U}$ occurs associated with Fe-Zn nanoparticles as 
52 small as $\sim 10 \mathrm{~nm}$ without forming crystalline phases. ${ }^{5}$ In these instances the $\mathrm{U}$ concentration is

53 very low ( $\sim \mathrm{wt} \%$ at maximum), indicating the adsorption of $\mathrm{U}$ oxides, volatilized at $>\sim 1,900 \mathrm{~K}$

54 from partially oxidized uranium dioxide. ${ }^{5,9,10}$ Although the total amount of $\mathrm{U}$ released from the

55 FDNPP, estimated from limited data as $3.9 \times 10^{6} \mathrm{~Bq},{ }^{11}$ may be ten orders of magnitude lower

56 than the total released Cs radioactivity, acquiring knowledge on the released $\mathrm{U}$ is important in

57 order to understand the environmental impact of the FDNPP accident, and to provide much

58 needed data on the status of the melted nuclear fuels in the damaged reactors, of which the

59 mixture with structural materials is called "debris." At present, the decommissioning of the

60 damaged FDNPP reactors is the most challenging operation at the site because of the high

61 radiation fields inside the reactors $(\sim 80 \mathrm{~Sv} / \mathrm{h}$ at Unit 2 on March 17, 2017 as determined by

62 Tokyo Electric Power Company (TEPCO)) and resulting lack of data. ${ }^{12}$ Thus, the more

63 information on the physical and chemical properties of the fuel the better, as it is essential for the

64 removal and future management of the debris. Fragments of nuclear fuels bearing U, other

65 actinides, and fission products, which have not been found to date in Fukushima, are also known

66 to be an important medium for influencing the mobility and bioavailability of radionuclides after

67 nuclear accidents. ${ }^{13,14}$ In turn, they influence impact and risk assessments. ${ }^{15}$ Further, the fragment

68 particles are the only direct evidence to provide information on the physical and chemical

69 properties of real debris remaining inside the damaged reactors. The present study reports, for the

70 first time, direct observation of nano-sized "debris fragments" released from the FDNPP based

71 on the detailed atomic-resolution analysis in order to further elucidate their formation processes

72 and partially assess their chemical properties.

\section{Materials and Methods}


76 The sampling campaign was conducted at two locations on March 16, 2012. Surface soils were

77 collected from the top $\sim 1 \mathrm{~cm}$ of soil at an aquaculture center (AQC) and Ottozawa (OTZ) located

$78 \sim 2 \mathrm{~km}$ south and $\sim 4 \mathrm{~km}$ west of the FDNPP in Okuma Town, Futaba County, Fukushima,

79 respectively. See map in Furuki et al. ${ }^{5}$ Six soils were collected from a side ditch at AQC and 15

80 soils were collected a paddy field at QTZ. The soils were primarily composed of clay minerals,

81 quartz and feldspars. Three CsMPs were separated from the soils: one from AQC and two from

82 OTZ. The CsMPs were labeled as AQC-A, OTZ-A, and OTZ-B, which correspond to AQC2,

83 OTZ6, and OTZ9, respectively, in the Kyushu University CsMP archive.

\section{Isolation of CsMPs}

85 The procedure for separating CsMPs from soil samples follows that outlined in our previous

86 study. Initially, the soil samples were sieved through a $114-\mu \mathrm{m}$ mesh. The powder samples were

87 dispersed on grid paper and covered with a plastic sheet; an imaging plate (IP, Fuji film, BAS-

88 SR 2025) was then placed on the samples for 5-25 minutes. The autoradiograph image was

89 recorded with a pixel size of 50-100 $\mu \mathrm{m}$ using an IP reader. After identifying the positions of

90 intense radioactive spots, droplets of pure water were added to these positions and then drawn

91 using a pipette to make a suspension with a small amount of soil particles. The procedure was

92 repeated until the suspension did not contain a significant amount of soil particles.

93 Thereafter, using double-sided carbon tape, the position containing a hot spot was sampled. The

94 section containing the hot particle was cut as small as possible using a blade, and the pieces were

95 checked by autoradiograph imaging, so that scanning electron microscopy (SEM) observation

96 could be performed to locate the CsMPs with maximum efficiency. The pieces were placed on an 
97 aluminum plate and coated with carbon using a carbon coater (SANYU, SC-701C) prior to SEM

98 analysis. The CsMP was found using an SEM (Shimadzu, SS550 and Hitachi, SU6600) equipped

99 with energy dispersive X-ray spectrometry (EDX, EDAX Genesis). The acceleration voltage was

$100 \quad 5-25 \mathrm{kV}$ for imaging details of the surface morphology and 15-25 kV for elemental analysis,

101 including area analysis and elemental mapping.

102 Preparation of the TEM specimen

103 A focused ion beam (FIB) system (FEI, Quanta 3D FEG 200i Dual Beam) was utilized to

104 prepare thin foils of individual CsMPs with diameters of a few $\mu \mathrm{m}$. The ion source was Ga,

105 while $\mathrm{W}$ deposition was used to minimize damage by the ion bombardment. The current and

106 acceleration voltage of the ion beam were adjusted to be $100 \mathrm{pA}$ to $30 \mathrm{nA}$ and 5-30 kV

107 depending on the progress of thinning and sample properties such as hardness and size. The

108 thinned piece was attached to the semilunar-shaped $\mathrm{Cu}$ grid for FIB and further thinned by an ion

109 beam at $5 \mathrm{kV}$.

\section{Transmission electron microscopy (TEM) analysis}

111 High-resolution TEM (HRTEM) with energy dispersive X-ray analysis (EDX) and high-angle

112 annular dark-field scanning transmission electron microscopy (HAADF-STEM) were performed

113 using JEOL JEM-ARM200F and JEM-ARM200CF with an acceleration voltage of $200 \mathrm{kV}$. The

114 JEOL Analysis Station software and Thermo Scientific NSS software were used to control the

115 STEM-EDX mapping. To minimize the effect of sample drift, a drift-correction mode was used

116 during acquisition of the elemental map. The STEM probe size was $\sim 0.13 \mathrm{~nm}$, generating $\sim 140$

$117 \mathrm{pA}$ of current when $40 \mu \mathrm{m}$ of the condenser lens aperture was inserted. The collection angle of

118 the HAADF detector was $\sim 97-256 \mathrm{mrad}$. 
120 The 3D tomography of the Fe-U particle in OTZ-A was performed in HAADF-STEM image

121 mode using a JEOL JEM-ARM200CF. The HAADF-STEM images were acquired by tilting

122 from $-70^{\circ}$ to $+69^{\circ}$ at intervals of $1^{\circ}$. ImageJ (NIH), TEMography ${ }^{\mathrm{TM}}$ (SYSTEM IN FRONTIER),

123 and Amira (Maxnet) were used to reconstruct the 3D structure.

\section{Gamma spectrometry}

125 The ${ }^{134} \mathrm{Cs}$ and ${ }^{137} \mathrm{Cs}$ radioactivities of the CsMPs were determined using gamma spectrometry.

126 The radioactivity of an additional micro-particle with a size of $\sim 400 \mu \mathrm{m}$ obtained from the

127 surface soil in Fukushima was precisely determined at the radioisotope center in Tsukuba

128 University, Japan, and utilized as a standard point specimen for ${ }^{134} \mathrm{Cs}$ and ${ }^{137} \mathrm{Cs}$. The radioactivity

129 of the point source standard was 23.9 Bq for ${ }^{134} \mathrm{Cs}$ and $94.6 \mathrm{~Bq}$ for ${ }^{137} \mathrm{Cs}$ as of September 29 ,

130 2015. The measurement of radioactivity was performed on the CsMPs and the point source

131 standard using Ge semi-conductor detectors GMX23 (SEIKO E\&G) and GX6020 (Canberra) at

132 the Center for Radioisotopes in Kyushu University, Japan. The acquisition times were: $83121 \mathrm{~s}$

133 for AQC-A using GMX23; 87481 s for OTZ-B using GMX23; and 70000 s for OTZ-A using

134 GX6020.

\section{Results}

137 In the present study, uranium oxide nanoparticles were discovered to be associated with three

138 CsMPs that were separated from soils collected within $\sim 4 \mathrm{~km}$ of the FDNPP; at an aquaculture

139 center (AQC) and Ottozawa (OTZ). ${ }^{5}$ It is extremely difficult to find isolated uranium oxide 
140 nanoparticle in the environment surrounding the FDNPP. In the present study, the CsMP was a

141 key to the discovery of uranium oxide nanoparticles. The CsMPs are designated as AQC-A,

142 OTZ-A and OTZ-B. The radioactivity of the CsMPs and other relevant parameters are

143 summarized in Table $\mathrm{S} 1$. The ${ }^{134} \mathrm{Cs} /{ }^{137} \mathrm{Cs}$ activity ratios were determined to be $0.98-1.07$, which

144 approximately corresponds to the burnup calculated for the reactors at the FDNPP. ${ }^{16}$ Scanning

145 electron microscopy energy dispersive X-ray analysis (SEM-EDX) revealed that all CsMPs are 146 mainly composed of $\mathrm{Si}, \mathrm{Fe}, \mathrm{Zn}$ and $\mathrm{Cs}$ (Figure 1).

\section{OTZ-A}

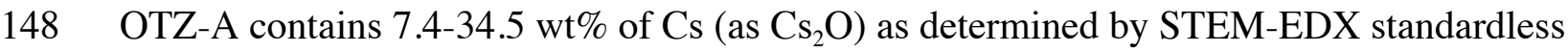

149 analysis (Table S2 and Figure S1A). In addition to large angular pores and some inclusions,

150 OTZ-A contained a Fe-oxide nanoparticle of $\sim 100 \mathrm{~nm}$ size, which was attached to the CsMP

151 surface (indicated by the white square in Figure 2A). A discrete U phase was observed within the

152 Fe-oxide nanoparticle (Figure S1B). HAADF-STEM and HRTEM images of the same Fe-oxide

153 nanoparticle, further thinned by FIB, revealed the presence of two U-oxide nanoparticles of $\sim 10$

$154 \mathrm{~nm}$ and $\sim 30 \mathrm{~nm}$ size (Figure 2B, S2A, and S2C). These textures were not created by electron

155 beam irradiation during TEM observation but rather represent the original phases because the

156 radiation-induced formation of U-oxide nanocrystals requires much higher doses than that used

157 in this study. ${ }^{17}$ Based on the atomic-resolution HAADF-STEM and the selected area electron

158 diffraction (SAED) pattern, the Fe-oxide and U-oxide nanoparticles were identified to be

159 magnetite $\left(\mathrm{Fe}_{3} \mathrm{O}_{4}\right)$ and uraninite $\left(\mathrm{UO}_{2+\mathrm{X}}\right)$, respectively (Figure $2 \mathrm{C}$ and the SAED viewed from the

160 other zone axis in Figure S2B). The two SAEDs explicitly reveal that these two phases are

161 oriented with same zone axes, indicating the structural relation of epitaxial growth between

162 magnetite and uraninite (Figure 2D). High-resolution HAADF-STEM with atomic-resolution 
163 STEM elemental maps clearly show an array of $U$ atoms within the uraninite nanoparticle and 164 arrayed Fe atoms in the same direction. The HR-HAADF-STEM image (Figure 2C) displays 165 enhanced contrast at every 4 or 5 atomic columns, both in $a$ and $b$ axes within the portion of the 166 U-oxide nanoparticle. This is due to the over- or under-lying Fe atoms in the same orientation 167 along the projected zone axis, because magnetite and uraninite are both isometric with unit cell 168 parameters of $0.83958 \mathrm{~nm}^{18}$ and $0.54682 \mathrm{~nm}^{19}$, respectively.

169 The three dimensional electron tomography of the magnetite nanoparticle also revealed the 170 presence of two euhedral uraninite nanocrystals completely enclosed in a part of euhedral 171 magnetite crystal oriented toward the same direction, which is consistent with crystallographic 172 relation of epitaxial growth (Figure 2E and 2F, and movie S1). The magnetite nanoparticle is

173 also associated with trace concentrations of Tc and Mo as revealed by the EDX analyses (Figure 174 S2D). The line scan analysis of a traverse of the further thinned specimen reveals that Tc and Mo 175 are present on the exterior of the magnetite nanoparticle (Figure 2G). Hence, the magnetite 176 containing the uraninite nanoparticles formed without impurities that can be detected by EDX 177 ( $\sim 0.1 \mathrm{wt} \%)$, and Tc and Mo were subsequently adsorbed to the surface. The Tc association 178 should have occurred inside the reactors, because the Tc concentration is diluted when dispersed 179 to the environment. Because Tc isotopes scarcely occur naturally but are generated as a fission 180 product in nuclear reactor, ${ }^{20}$ the Tc occurrence over the surface of the magnetite nanocrystal 181 provides strong evidence that the uraninite nanocrystals embedded in magnetite nanocrystal 182 originated inside the reactors. Thus, it is identified as nanoscale fragment of reactor debris. 
184 Figure 3A shows a HAADF-STEM image of the cross-section of AQC-A, displaying domains 185 with high Cs concentration (high contrast at the area 1) (Table S2) in a porous matrix that has 186 lower Cs concentrations (represented by area 5). The texture is indicative of aggregation of

187 individual dense CsMP particles. Within the porous portion of the CsMP, a euhedral Fe-oxide 188 nanocrystal of $\sim 400 \mathrm{~nm}$ size was found, which also had an embedded uranium dioxide 189 nanoparticle of $\sim 70 \mathrm{~nm}$ size (Figure 3B). This $\mathrm{U}$ oxide nanoparticle had a similar shape, 190 composition, and host phase as those characterized in OTZ-A. It is important to note that this

191 TEM specimen was prepared by FIB and the TEM image shows the cross section of the CsMP.

192 Thus, the Fe-oxide containing uraninite nanoparticle is encapsulated in the CsMP. Because the

193 CsMP formed inside the reactors, the Fe-oxide nanoparticle with the embedded U-oxide

194 nanoparticle originated from the reactors as well, indicating that the nanoparticles are nano195 fragments of reactor debris as well as the one found in OTZ-A.

196 OTZ-B

197 OTZ-B occurs as an aggregate of at least three spherical CsMPs each of $\sim 1 \mu \mathrm{m}$ size (Figure 4A), 198 and their compositions were determined to be 2.8-32.2 wt $\%$ of $\mathrm{Cs}_{2} \mathrm{O}, 9.1-26.1 \mathrm{wt} \%$ of $\mathrm{Fe}_{2} \mathrm{O}_{3}, 0.0-$ $1997.3 \mathrm{wt} \%$ of $\mathrm{ZnO}$, and 45.6-73.7 wt\% of $\mathrm{SiO}_{2}$ (Figure $\mathrm{S} 3$ and Table S2). This is consistent with 200 the composition of CsMPs described in the literature. ${ }^{5,9}$ Notably, eleven U-Zr-oxides 201 nanoparticles were found within this aggregate (Figure 4A and B). All of the U-Zr particles were 202 characterized as solid solutions as revealed by the magnified image and the elemental maps 203 (Figure 4C). See SI (page S7) for further information on the identification of solid solution. 204 Further, the $\mathrm{Zr}$ and $\mathrm{U}$ distribution are almost homogeneous within the individual grains. The 205 molar fraction of $\mathrm{U}$ in the $\mathrm{U}-\mathrm{Zr}$-oxides, $\mathrm{U} /(\mathrm{U}+\mathrm{Zr})$, determined by STEM-EDX analysis, varied 206 widely between the particles, ranging from 0.14 to 0.91 (Figure 4D). 
207 After further thinning of OTZ-B by FIB, the U-Zr-oxides nanoparticles labelled as 1 and 2

208 (Figure 4C and E) were identified to be uraninite and cubic zirconia based on the SAED patterns,

209 respectively. Note, the extra diffraction maxima, which are absent due to an extinction rule in the

210 cubic structure, e.g., 210 and 120, appeared in the pattern because of the substitution of $U$ atoms

211 in the solid solution as shown by the simulated diffraction pattern for cubic $\mathrm{ZrO}_{2}$ with $25 \%$

212 substitution of U for $\mathrm{Zr}$ (Figure S4). High-resolution HAADF-STEM images and the SAED

213 patterns reveal that both particles are single crystals (Figure 4E) and that particle 1 has pores of

$214 \sim 6 \mathrm{~nm}$ diameter (Figure S5A and B) and a few defects (Figure S5B-E). The U/(U+Zr) molar

215 ratios are 0.91 for particle 1 and 0.17 for particle 2 , indicating that $\mathrm{U}-\mathrm{Zr}$-oxide solid solution can

216 form with a large variation in the mixing ratio. In addition, similar to OTZ-A, Tc occurrence was

217 observed in Fe-rich areas (Figure S6), providing further indication that the CsMP and the U-Zr-

218 oxide nanoparticles are derived from the FDNPP.

220 Discussion

\section{Formation processes of the reactor debris fragments}

222 The U nanoparticles and the Fe-oxide nanoparticles in AQC-A and OTZ-A have uraninite

$223\left(\mathrm{UO}_{2+\mathrm{X}}\right), \mathrm{X}<0.33$ and magnetite structures, respectively, with octahedral crystalline shape. The

224 Fe source for the magnetite was likely the stainless steel of the reactor pressure vessel (RPV)

225 and/or other metal parts of the fuel assembly. The chemical form of Fe has been considered to be

226 metallic in the fuel debris at the FDNPP based on the severe accident analysis calculations, ${ }^{21,22}$

227 though magnetite $\left(\mathrm{Fe}_{3} \mathrm{O}_{4}\right)$ particles were characterized in the present study. The molten Fe metal

228 can slightly vaporize above the melting temperature, $1811 \mathrm{~K}, 3$ and the vaporized Fe can easily 
229 bond to oxygen to form Fe-oxide nanoparticles, mainly magnetite. ${ }^{24}$ However, the

230 vaporization/condensation mechanism may not account for all of the formed magnetite, because

231 the shape of the magnetite nanoparticles produced through vaporization/condensation processes

232 in welding fumes are generally spherical ${ }^{25,26}$ which is clearly different from the octahedral shape

233 observed in OTZ-A and AQC-A. Rather, their octahedral morphology indicates a slower

234 crystallization processes similar to the euhedral ferrous particles and uraninite nanoparticles

235 found in the Three Mile Island reactor unit 2 (TMI-2). ${ }^{27,28}$ The occurrence of epitaxially grown

236 magnetite indicates that a part of Fe metal was oxidized before crystallization over the uraninite

237 nanocrystals. That is, the epitaxial growth of magnetite over uraninite excludes the possibility of

238 the initial formation of Fe metal over the uraninite nanoparticles. Considering the large

239 difference in the melting points of magnetite and $\mathrm{UO}_{2+\mathrm{X}} ; 1863 \mathrm{~K}$ and $2900 \mathrm{~K}$, respectively, ${ }^{27}$ the

240 solidification of uraninite nanocrystals would first proceed within the Fe oxides melts as its

241 cools, followed by the epitaxial growth of magnetite over uraninite nanocrystals.

242 The U-Zr-oxide nanoparticles in OTZ-B likely formed from a U-Zr-oxide melt, which would

243 have resulted from the interaction of molten fuel and $\mathrm{ZrO}_{2}$ that had previously been produced

244 through the reaction of zircalloy and steam at high temperature $>\sim 1500 \mathrm{~K}^{6}{ }^{6}$ The liquidus

245 temperature of $\mathrm{U}-\mathrm{Zr}$ oxides is as high as $\sim 2800-3000 \mathrm{~K}$ depending on the $\mathrm{Zr}$ fraction ${ }^{29}$ which is,

246 in general, slightly lower than the melting points of pure $\mathrm{UO}_{2+\mathrm{X}}$ and $\mathrm{ZrO}_{2}, 2900 \mathrm{~K}$ and $2960 \mathrm{~K}$,

247 respectively. ${ }^{27}$ This indicates that the particle was locally heated higher than $2800 \mathrm{~K}$. The

248 melting temperature can be even lower than $2800 \mathrm{~K}$ in corium, which is a lava-like melt of the

249 fuels, because the liquidus and solidus temperatures of the hyperstoichiometric U oxides (up to

$250 \mathrm{UO}_{2.21}$ ) decrease to as low as $2800 \mathrm{~K}$ and $2400 \mathrm{~K}$, respectively. ${ }^{30} \mathrm{In}$ addition, the wide range in

251 the composition of $\mathrm{U}-\mathrm{Zr}$ oxides $(\mathrm{U} /(\mathrm{U}+\mathrm{Zr})=0.14-0.91)$, indicates that the melt did not form a 
252 large-scale pool of homogeneous composition. Rather, the U-Zr-oxide eutectic occurred

253 heterogeneously at the micron scale due to spatial variations in the chemistry.

254 According to the $\mathrm{U}-\mathrm{Zr}-\mathrm{O}$ phase diagram, when the melt composition is close to the $\mathrm{ZrO}_{2}$ end255 member $(\mathrm{U} /(\mathrm{U}+\mathrm{Zr})=0.14)$, the cubic phase is stable below the solidus temperature, and there is 256 a structural transition from cubic to tetragonal at $\sim 2400 \mathrm{~K}$ ( $2620 \mathrm{~K}$ in case of stoichiometric 257 zirconia) when cooled down. ${ }^{31,32}$ Although the cubic phase is stable only above $\sim 2400 \mathrm{~K}$ in the 258 phase diagram, the $\mathrm{U}-\mathrm{Zr}$ oxides retained the cubic structure at ambient temperature in OTZ-B, 259 most likely because of rapid cooling of the liquid U-Zr-oxides droplets. In case of the TMI-2, U$260 \mathrm{Zr}$ oxide was reported to be tetragonal rather than monoclinic, which is stable at $<1300 \mathrm{~K}$ also 261 because of the rapid cooling process. ${ }^{32}$ The cubic U-Zr-oxide nanoparticles identified in the 262 present study probably formed by a more rapid cooling process than that which occurred at TMI2632.

264 From these data, part of the process that the FDNPP fuels experienced during the meltdown can 265 be summarized as the follows: Cooling waters vaporized and the steam reacted with $\mathrm{Zr}$ and $\mathrm{Fe}$ 266 forming their oxides after the loss of power to the cooling system; $\mathrm{UO}_{2}$, which is the main 267 composition of fuels, partially oxidized and volatilized at $>\sim 1,900 \mathrm{~K} \cdot{ }^{9,10}$ The fuel assemblies 268 melted unevenly with relatively less-irradiated fuels being heated to a higher temperature as 269 compared with the high burn-up fuels and volatilized as evidenced by the ${ }^{235} \mathrm{U} /{ }^{238} \mathrm{U}$ isotopic 270 ratio. ${ }^{9}$ The fuel assembly collapsed and moved to the bottom of RPV. The temperature increased

271 locally to at least $>2400 \mathrm{~K}$ based on the liquidus temperature of U-Zr-oxides. Locally-formed 272 oxides melted to a heterogeneous composition, including a small amount of the Fe oxides, ${ }^{27}$

273 which then became a source of Fe-U-single crystals and $\mathrm{U}-\mathrm{Zr}$-oxide eutectic phases.

274 Specifically, euhedral magnetite nanocrystals encapsulated euhedral uraninite nanocrystals, 
275 which would have crystallized slowly at this stage. Liquid U-Zr-oxides nano-droplets were

276 rapidly cooled and solidified to a cubic structure. When the molten fuels hit the concrete pedestal

277 of the primary containment vessel (PCV), $\mathrm{SiO}$ gas was generated at the interfaces between the

278 melted core and concrete, and instantly condensed to form CsMPs. ${ }^{5}$ The U-Zr-oxide

279 nanoparticles or the magnetite nanocrystals subsequently formed aggregates with CsMPs.

280 Finally, the reactor debris fragments were released to the environment along with CsMPs.

\section{Insights into the current status of debris properties}

282 Grambow and Poinssot ${ }^{33}$ have discussed the possible composition of corium, the risk, and its

283 stability in the damaged reactors at the FDNPP. In general, the amounts of fission products and

284 U remaining in the corium strongly depend on their volatility, which were classified into volatile

285 (Cs, I), semi-volatile (Ba, Tc, Mo), low volatility ( $\mathrm{Sr}, \mathrm{La})$, and nonvolatile (U) ${ }^{34}$ Based on the

286 properties of debris nano-fragments characterized in the present study and the other $\mathrm{U}$

287 occurrences within CsMPs, ${ }^{5,9}$ we can surmise that at least three types of U occurrence that

288 formed during the meltdown of the FDNPP reactors: (i) trace amounts of U were associated with

$289 \mathrm{Fe}-\mathrm{Zn}$-oxide nanoparticles embedded in $\mathrm{SiO}_{2}$ matrix within $\mathrm{CsMP},{ }^{5}$ (ii) uraninite nanocrystals

290 without detectable impurities, which were embedded within the Fe-oxide; (iii) eutectic U-Zr-

291 oxide nanoparticles also formed. The type (i) U was described in detail in our previous studies. ${ }^{5,9}$

292 The types (ii) and (iii) are the U occurrence the newly discovered phases described in this paper.

293 The type (i) particles may be formed by volatilization of the partially oxidized fuels with low

294 burnups and the volatilized $\mathrm{U}$ adsorbed onto $\mathrm{Fe}-\mathrm{Zn}$-oxide nanoparticles based on the ${ }^{235} \mathrm{U} /{ }^{238} \mathrm{U}$

295 isotope ratio greater than the average ratio calculated from the burnup. ${ }^{9}$ Indeed, the

296 hyperstoichiometric $\mathrm{UO}_{2+\mathrm{X}}$ typically occurs during the meltdowns; $\mathrm{X}=0.03-0.14$ in case of the

297 TMI- $2^{28}$ and $X=0.23-0.42$ in bore sample of PHEBUS FPT1 test..$^{30,35}$ Despite the evidence of 
volatilization recorded in the CsMPs, the amount of molten fuels that have experienced

299 volatilization is likely to be small. ${ }^{33}$ The existence of magnetite and uraninite phases is indicative

300 of the redox environment under accidental conditions: they appear to be more reducing than

301 oxidizing, probably due to the large quantities of metal present in the system $(\mathrm{Fe}, \mathrm{Zr})$.

302 Besides the nano-scale dimension, the compositions of the nano-fragments released from the

303 FDNPP, types (ii) and (iii), are comparable to those of the debris previously obtained from both

304 TMI-2 and Chernobyl..$^{27,32,36}$ In the present study, one of the U-rich particles (1 in Figure 4C,

305 Figure S5A) has pores with $\sim 6 \mathrm{~nm}$ in size and defects; whereas, the Zr-rich particles (e.g., 2 in

306 Figure 4C and E) have no pores, suggesting that U-Zr-oxide in the debris contains micron-sized

307 inclusion of gas phases, such as fissionogenic noble gases similar to those in irradiated fuels.$^{37}$

308 The Nuclear Energy Agency ${ }^{21,22}$ reported that elemental Fe is the dominant Fe phase in the

309 debris in the damaged reactors at the FDNPP, while magnetite should not be present or occur in

310 negligibly small amount based on the calculation. In contrast to their results, elemental Fe was

311 not characterized in the limited samples of the present study, although our results are consistent

312 with the last part of their conclusion. We do not propose that Fe oxide is dominant in the debris

313 but rather suggest that the occurrence of Fe-oxide is possible at the nano-scale with various

314 important features. The present study clearly reveals the presence of magnetite as a reactor debris

315 component and demonstrates the possible close association of uraninite as evidenced in AQC-A

316 and OTZ-A. Magnetite is also closely associated with Tc in the present samples (Figure 2G,

317 Figure S2 and S6). The Tc occurrence on the surface of magnetite and the encapsulation by the

318 CsMP exclude the possibility of magnetite formation as an alteration phase after release into the

319 environment. On the other hand, because ${ }^{99} \mathrm{Tc}$ is a fission product of major concern due to its

320 long half-life, $2.1 \times 10^{5}$ years $^{20}$ which is normally contained in fuel epsilon phase $(\mathrm{s})^{38}$ and with 
321 small portions within the uraninite matrix, the occurrence of Tc in the debris is another issue that

322 needs to be understood. Some Tc, which is classified as semi-volatile, ${ }^{39}$ likely volatilized in the

323 reactors and then was adsorbed and incorporated into the magnetite structure ${ }^{40,41}$ during the

324 FDNPP reactor unit meltdowns. Technetium can volatilize as oxidized forms at $\sim 1200 \mathrm{~K}$

325 depending on the oxygen potential, ${ }^{10}$ and the oxidation state of the Tc incorporated in the

326 magnetite structure is likely to be Tc(IV), particularly when the other metals with low reducing

327 potential were incorporated together ${ }^{42}$ as detected in the present study. Since Fe phases, mostly

328 Fe metal, are expected to occur as a major component of debris remaining in the damaged

329 reactors, magnetite, which potentially forms at the surface of the Fe portion of the reactor debris,

330 can contain not only uraninite but also other long-lived FPs, such as Tc.

331 The current status of debris in the damaged reactors was partially elucidated in the present study.

332 Although the debris fragments are limited and extremely small, the physicochemical properties

333 and the plausible formation processes give some insights to the partial properties of debris; in

334 turn, this may provide useful information to the FDNPP decommissioning strategy. The gap

335 between the evidence found in the present study and the results of the severe accident analysis

336 code calculations, ${ }^{21,22}$ such as the state of Fe speciation, strongly suggests the need for further

337 detailed investigation on the debris, although it is extremely difficult to find the debris fragments

338 in the environment. In addition, because several years have passed since the debris formed in the

339 damaged reactors, the debris may be chemically altered due to contact with the injected water:

340 first high-salinity seawater and later fresh water. ${ }^{43}$ The instant release fraction (IRF) of the

341 radionuclides that are unbound to debris matrix (estimated to be 5-10\% of the total inventory)

342 has already been leached from the corium. ${ }^{33,44}$ Uraninite compounds in debris are known to

343 dissolve relatively rapidly and to be controlled by surface interactions including oxidants 
344 produced by the radiolysis of the water under oxidizing conditions, such as in the FDNPP, as

345 compared with reducing conditions in a deep geologic repository. ${ }^{33,45}$ Thus, precipitation of the

346 secondary $\mathrm{U}$ phases over the debris surfaces and the retention of the other FP should be

347 considered as it is in the alteration of spent nuclear fuels, ${ }^{46}$ which are also constrained by the

348 initial state of debris that was partially determined in the present study.

\section{Environmental impacts of the released debris nano-fragments}

350 The release of reactor debris fragments from the FDNPP into the surrounding environment has

351 been, for the first time, explicitly revealed in the present study. The occurrence of debris

352 fragments with intrinsic uraninite particles can greatly influence the mobility and bioavailability

353 of the particle-associated radionuclides in ecosystem. ${ }^{15}$ Remarkably, the CsMPs are an important

354 medium for the transport of debris fragments in case of the FDNPP, although the possibility of

355 the debris fragment released unassociated with CsMPs is also high. Because of the small size and

356 association with CsMP, the mobility and stability of the reactor debris particles in Fukushima

357 might be different from those of coarse fuel particles found in Chernobyl, which are constrained

358 by the morphology and redox state. ${ }^{47}$ However, the uraninite nanocrystals characterized in the

359 present study were enwrapped by magnetite or CsMPs, suggesting that they are not presently in

360 contact with the fluid. The dissolution of glassy CsMPs may initially proceed depending on the

361 solution conditions similarly to the glass dissolution ${ }^{48}$ and eventually expose the debris nano-

362 fragments to fluids. Also, there is a high possibility of inhaling debris fragments along with

363 CsMPs because the size of CsMPs associated with debris nano-fragments characterized in the

364 present study is $<\sim 5 \mu \mathrm{m}$, which can reach to the deep respiratory system when inhaled. ${ }^{49}$ Further

365 work understanding the long-term behavior of FDNPP derived U particulates is now needed. 
366

367 


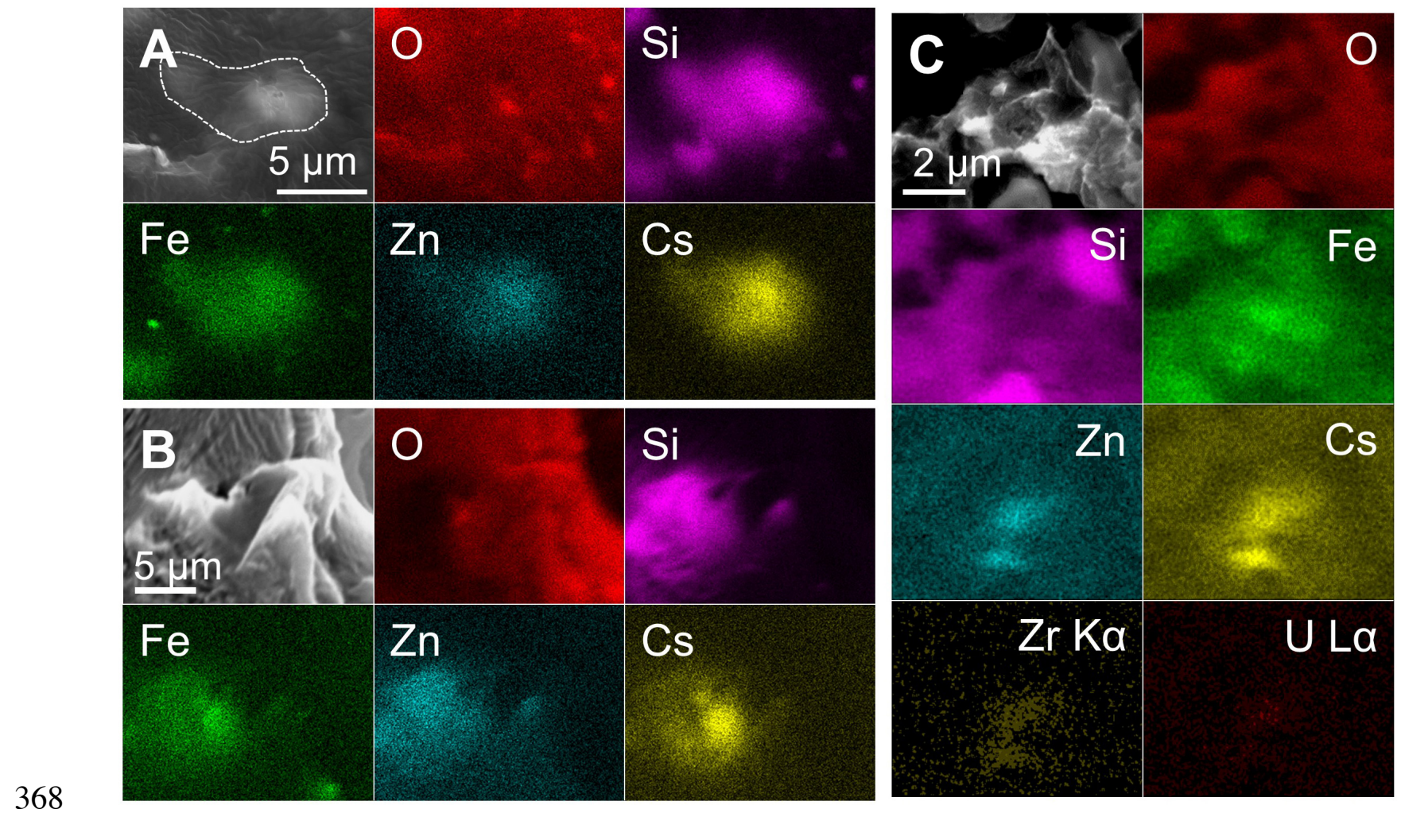

369 Figure 1. Secondary electron images of three CsMPs. (A) OTZ-A, (B) AQC-A and (C) OTZ-B, 370 and elemental maps of the major constituents obtained by SEM-EDX analysis. 

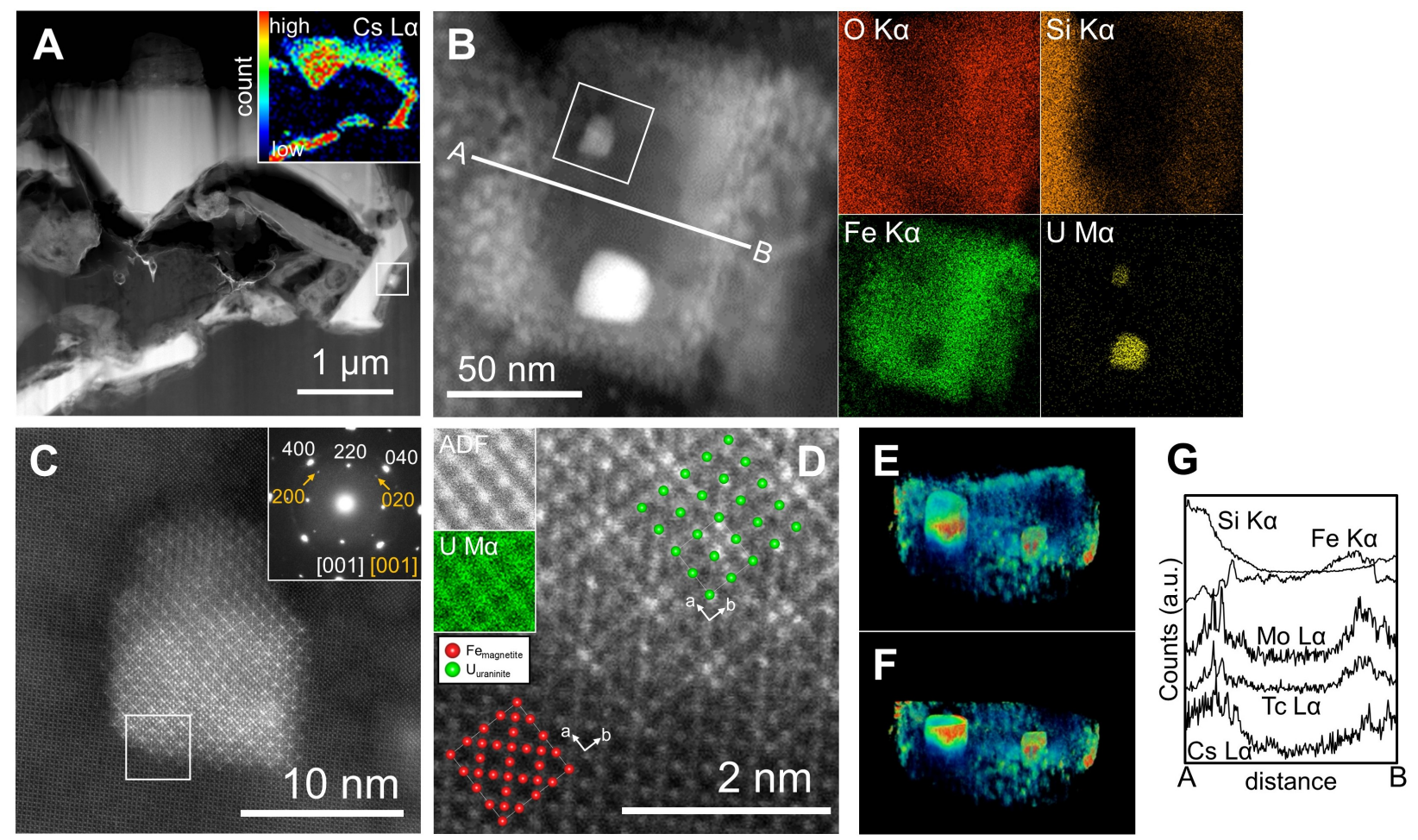

374 Figure 2. TEM characterization of the uraninite fragments in OTZ-A. (A) HAADF-STEM image

375 of the half part of OTZ-A and the STEM-EDX map of Cs L $\alpha$, of which the color represents the

376 X-ray counts. (B) HAADF-STEM image of the same Fe-U particle observed in Figure S1B after

377 thinning by FIB, and the elemental maps of the selected elements. The white square and line

378 segment $\mathrm{AB}$ are further characterized in Figure 2C and Figure 2G, respectively. (C) Magnified

379 image of the area indicated by the white square in Figure 2B and the SAED pattern, which are

380 collected from the area including both $\mathrm{Fe}$ oxide and $\mathrm{U}$ oxide nanoparticles. Indexes in white and

381 yellow letters corresponds to magnetite and uraninite structures, respectively. The white square is

382 further magnified in Figure 2D. (D) High-resolution HAADF-STEM image of the area indicated

383 by the white square in Figure 2C. Fe atoms (red) of magnetite structure and $\mathrm{U}$ atoms (green) of

384 uraninite structure are overlaid in the image. An atomic-column elemental map of $U$ is also

385 included. (E) Electron tomography showing the three-dimensional structure of uraninite

386 nanoparticles in magnetite nanoparticle. See supplementary video file for further detail. (F) A 
387 cross-sectional view of uraninite nanoparticles embedded with the magnetite nanoparticle. A part 388 of the euhedral rectangular shape can be observed, although the top and bottom of this magnetite 389 nanoparticle was removed by the FIB thinning. (G) STEM-EDX line-scan analysis of the 390 traverse AB in Figure 2B.

391

392 

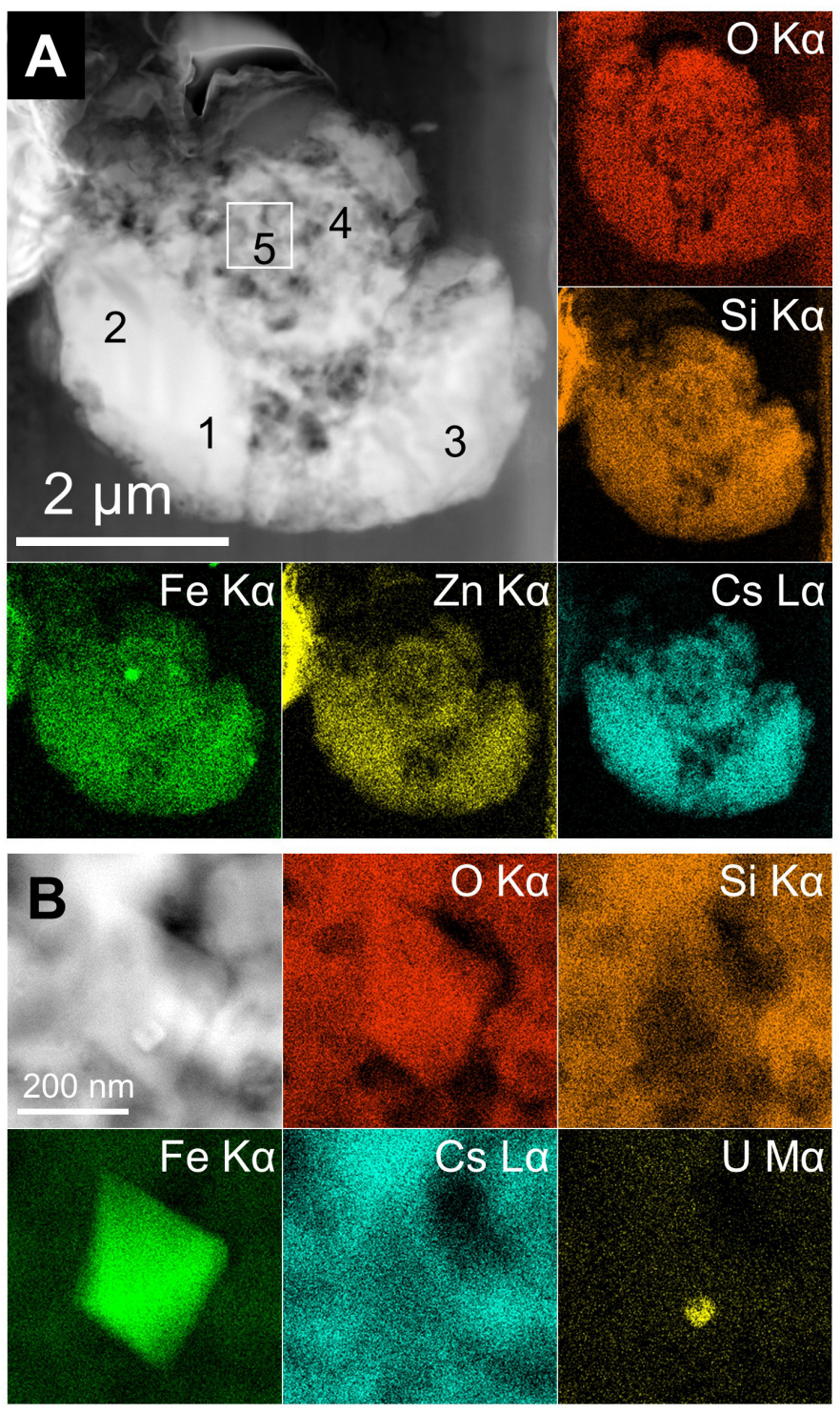

394 Figure 3. TEM characterization of the uraninite fragments in AQC-A. (A) HAADF-STEM 395 image of AQC-A and the elemental map of the major constituents. The numbers represents the 396 analytical points by STEM-EDX in Table 2. (B) Enlarged image of the area indicated by the 397 white square in Figure 3A associated with the elemental maps. 

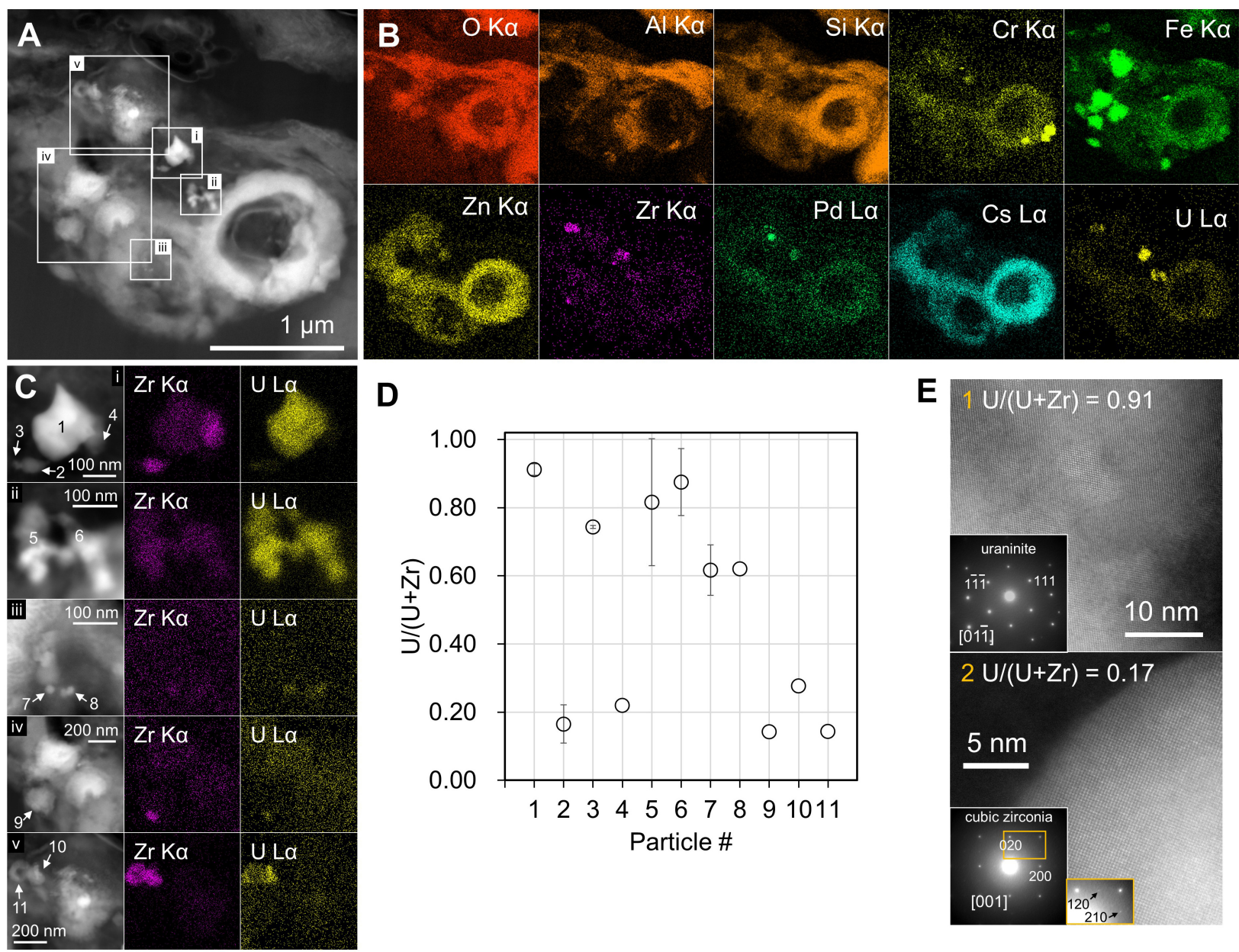

Figure 4. TEM characterization of the U-Zr oxide fragments in OTZ-B. (A) HAADF-STEM

402 image of the aggregates of CsMPs in OTZ-B, where U-Zr oxide nanoparticles are present. (B)

403 The elemental maps of major constituents in the Figure 4A. (C) Magnified HAADF-STEM

404 images for the areas indicated by the white square with Roman numbers in Figure 4A associated

405 with the elemental maps of $\operatorname{Zr}(\mathrm{K} \alpha)$ and $\mathrm{U}(\mathrm{L} \alpha)$. The Arabic numbers indicated by the arrows

406 correspond to the particle numbers in Figure 4D. (D) The molar ratios of U/(U+Zr) analyzed

407 using STEM-EDX. The ratios reveal the average values; $\mathrm{n}=7$ for particle $1, \mathrm{n}=5$ for particle 2,

408 and $n=2$ for particles $3,5,6$ and 7 , and $n=1$ for the others without error bar. The error bars show

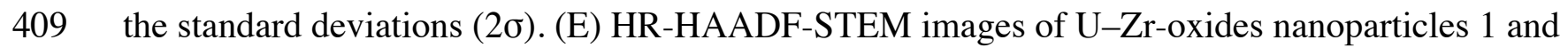

4102 in Figure $4 \mathrm{C}$ associated with the SAED patterns. U-rich particle $1(\mathrm{U} /(\mathrm{U}+\mathrm{Zr})=0.91)$ is 
411 identified as uraninite structure, and $\mathrm{Zr}$-rich particle $2(\mathrm{U} /(\mathrm{U}+\mathrm{Zr})=0.17)$ as cubic zirconia

412 structure. The magnified SAED pattern with yellow frame is inserted for particle 2.

\section{Supporting Information}

415 Supplementary sections present ancillary STEM data and information on the radionuclide 416 content of the CsMPs as determined by radiometric counting.

418 ASSOCIATED CONTENT

419 Figure S1. Results of STEM-EDX analysis of OTZ-A and the Fe-U oxide particle.

420 Figure S2. TEM results of uraninite nanoparticles embedded in magnetite nanoparticle associated 421 with OTZ-A.

422 Figure S3. STEM-EDX analysis of OTZ-B.

423 Figure S4. Schematic illustration of zirconia structures (top panels) and the simulated SAED 424 patterns viewed along [001] (bottom panels).

425 Figure S5. Results of STEM analysis of U-Zr oxide nanoparticle in OTZ-B.

426 Figure S6. Evidence of Tc occurrence in OTZ-B revealed by STEM-EDX analysis.

427 Table S1. Summary of the particle size, radioactivity and radioactivity ratio of OTZ-A, AQC-A 428 and OTZ-B. 
429 Table S2. Chemical composition (wt. \%) of the area analysis on OTZ-A, AQC-A and OTZ-B as 430 determined by STEM-EDX standardless analysis.

431 Movie S1. The three dimensional electron tomography of Fe-U particle in OTZ-A.

433 AUTHOR INFORMATION

\section{Corresponding Author}

435 *E-mail: utsunomiya.satoshi.998@m.kyushu-u.ac.jp

\section{Author Contributions}

437 S.U. conceived the idea, designed all experiments. A.O. conducted TEM analysis. A.O. and S. U. 438 wrote the manuscript. J.I., M.S., T.K., G.F., and R.I. performed separation of CsMPs and SEM 439 analysis. T.O. provided navigation during field research in Fukushima. S.Y. performed gamma 440 spectroscopy at Tsukuba University. G.T.W.L, B.G., and R.C.E. participated in the discussion 441 and interpretation of the results and helped to write the paper.

\section{Notes}

443 The authors declare no competing financial interests.

\section{ACKNOWLEDGMENT}

446 The authors are grateful to Dr. Watanabe for her assistance on SEM analyses at the Center of 447 Advanced Instrumental Analysis, Kyushu University. This study is partially supported by JST 448 Initiatives for Atomic Energy Basic and Generic Strategic Research and by a Grant-in-Aid for 449 Scientific Research (KAKENHI) from the Japan Society for the Promotion of Science 
450 (16K12585, 16H04634, No. JP26257402). SU is also supported by The Mitsubishi Foundation 451 /Research Grants in the Natural Sciences and by ESPEC Foundation for Global Environment 452 Research and Technology (Charitable Trust) (ESPEC Prize for the Encouragement of 453 Environmental Studies). G. L acknowledges UK NERC funding (NE/M014088/1). The findings 454 and conclusions of the authors of this paper do not necessarily state or reflect those of the JST.

\section{REFERENCES}

457 (1) Steinhauser, G.; Brandl, A.; Johnson, T. E. Comparison of the Chernobyl and Fukushima

(2) Chino, M.; Nakayama, H.; Nagai, H.; Terada, H.; Katata, G.; Yamazawa, H. Preliminary

\section{(3) Devell, L.; Johansson, K. Specific Features of Cesium Chemistry and Physics Affecting} Reactor Accident Source Term Predictions; SKI Report 94:29, Swedish Nuclear Power Inspectorate: Stockholm, Sweden, 1994.

(4) Adachi, K.; Kajino, M.; Zaizen, Y.; Igarashi, Y. Emission of spherical cesium-bearing 2554. 
470

471

472

473

474

475

476

477

478

479

480

481

482

483

484

485

486

487

488

489

(5) Furuki, G.; Imoto, J.; Ochiai, A.; Yamasaki, S.; Nanba, K.; Ohnuki, T.; Grambow, B.;

Ewing, R. C.; Utsunomiya, S. Caesium-rich micro-particles: A window into the meltdown events at the Fukushima Daiichi Nuclear Power Plant. Sci.Rep. 2017, 7, 42731.

(6) Nuclear Safety in Light Water Reactors: Severe Accident Phenomenology; Sehgal, B. R., Ed.; Elsevier: Amsterdam, The Netherlands, 2012.

(7) Abe, Y.; Iizawa, Y.; Terada, Y.; Adachi, K.; Igarashi, Y.; Nakai, I. Detection of uranium and chemical state analysis of individual radioactive microparticles emitted from the Fukushima nuclear accident using multiple synchrotron radiation X-ray analyses. Anal. Chem. 2014, 86 (17), 8521-8525.

(8) Kogure, T.; Yamaguchi, N.; Segawa, H.; Mukai, H.; Motai, S.; Akiyama-Hasegawa, K.; Mitome, M.; Hara, T.; Yaita, T. Constituent elements and their distribution in the radioactive Cs-bearing silicate glass microparticles released from Fukushima nuclear plant. Microscopy 2016, 65 (5), 451-459.

(9) Imoto, J.; Ochiai, A.; Furuki, G.; Suetake, M.; Ikehara, R.; Horie, K.; Takehara, M.; Yamasaki, S.; Nanba, K.; Ohnuki, T.; et al. Isotopic signature and nano-texture of cesiumrich micro-particles: Release of uranium and fission products from the Fukushima Daiichi Nuclear Power Plant. Sci. Rep. 2017, 7 (1), 5409.

(10) Hiernaut, J.-P.; Wiss, T.; Papaioannou, D.; Konings, R. J. M.; Rondinella, V. V. Volatile fission product behaviour during thermal annealing of irradiated $\mathrm{UO}_{2}$ fuel oxidised up to $\mathrm{U}_{3} \mathrm{O}_{8}$. J. Nucl. Mater. 2008, $372(2-3), 215-225$. 
(11) Sakaguchi, A.; Steier, P.; Takahashi, Y.; Yamamoto, M. Isotopic compositions of ${ }^{236} \mathrm{U}$ and Pu isotopes in "Black Substances" collected from roadsides in Fukushima prefecture: Fallout from the Fukushima Dai-ichi Nuclear Power Plant Accident. Environ. Sci. Technol. 2014, 48 (7), 3691-3697.

(12) Tokyo Electric Power Company (TEPCO) Website; http://www.tepco.co.jp/nu/fukushima-np/roadmap/2017/images2/d170727_08-j.pdf.

(13) Kuriny, V. D.; Ivanov, Y. A.; Kashparov, V. A.; Loshchilov, N. A.; Protsak, V. P.; Yudin, E. B.; Zhurba, M. A.; Parshakov, A. E. Particle-associated Chernobyl fall-out in the local and intermediate zones. Ann. Nucl. Energy 1993, 20 (6), 415-420.

(14) Salbu, B.; Krekling, T. Characterisation of radioactive particles in the environment. Analyst 1998, 123 (5), 843-850.

(15) Salbu, B.; Lind, O. C. Radioactive particles released to the environment from the Fukushima reactors-Confirmation is still needed. Integr. Environ. Assess. Manag. 2016, $12(4), 687-689$.

(16) Nishihara, K.; Iwamoto, H.; Suyama, K. Estimation of fuel compositions in FukushimaDaiichi Nuclear Power Plant; JAEA-Data/Code 2012-018, Japan Atomic Energy Agency: Ibaraki, Japan, 2012.

(17) Rey, A.; Utsunomiya, S.; Gimenez, J.; Casas, I.; de Pablo, J.; Ewing, R. C. Stability of uranium (VI) peroxide hydrates under ionizing radiation. Am. Mineral. 2009, 94 (2-3), 229-235. 
510

(18) Wechsler, B. A.; Lindsley, D. H.; Prewitt, C. T. Crystal structure and cation distribution in titanomagnetites $\left(\mathrm{Fe}_{3-\mathrm{x}} \mathrm{Ti}_{\mathrm{x}} \mathrm{O}_{4}\right)$. Am. Mineral. 1984, 69, 754-770.

(19) Wyckoff, R. W. G. Crystal Structures Vol.1; John Wiley: New York, 1963.

(20) Choppin, G. R.; Liljenzin, J.-O.; Rydberg, J. Radiochemistry and Nuclear Chemistry, 3rd Editio.; Butterworth-Heinemann: Woburn, MA, 2002.

(21) Nuclear Regulation Agency. Benchmark study of the accident at the Fukushima Daiichi Nuclear Power Plant (BSAF Project) - Phase I summary report; NEA/CSNI/R(2015)18, Nuclear Energy Agency: Boulogne-Billancourt, France, 2015.

(22) Nagase, F.; Gauntt, R. O.; Naito, M. Overview and outcomes of the OECD/NEA benchmark study of the accident at the Fukushima Daiichi Nuclear Power Station. Nucl. Technol. 2016, 196 (3), 499-510.

(23) CRC Handbook of Chemistry and Physics, 95th Edition; Haynes, W. M., Lide, D. R., Bruno, T. J., Eds.; CRC Press, Taylor \& Francis Group: Boca Raton, FL, 2014.

(24) Sanibondi, P. Numerical investigation of the effects of iron oxidation reactions on the fume formation mechanism in arc welding. J. Phys. D. Appl. Phys. 2015, 48 (34), 345202.

(25) Jenkins, N. T.; Eagar, T. W. Chemical analysis of welding fume particles. Weld.J. 2005, $84(6), 87 \mathrm{~s}-93 \mathrm{~s}$.

(26) Carpenter, K. R.; Monaghan, B. J.; Norrish, J. Analysis of fume formation rate and fume particle composition for Gas Metal Arc Welding (GMAW) of plain carbon steel using different shielding gas compositions. ISIJ Int. 2009, 49 (3), 416-420. 
(27) Olsen, C. S.; Jensen, S. M.; Carlson, E. R.; Cook, B. A. Materials interactions and temperatures in the Three Mile Island Unit 2 core. Nucl. Technol. 1989, 87 (1), 57-94.

(28) Bottomley, P. D.; Coquerelle, M. Metallurgical examination of bore samples from the

(29) Almjashev, V. I.; Barrachin, M.; Bechta, S. V.; Bottomley, D.; Defoort, F.; Fischer, M.;

Gusarov, V. V.; Hellmann, S.; Khabensky, V. B.; Krushinov, E. V.; et al. Eutectic crystallization in the $\mathrm{Fe}_{1.5}-\mathrm{UO}_{2+\mathrm{x}}-\mathrm{ZrO}_{2}$ system. J. Nucl. Mater. 2009, 389 (1), 52-56.

(30) Barrachin, M.; Chevalier, P. Y.; Cheynet, B.; Fischer, E. New modelling of the U-O-Zr

(31) Cohen, I.; Schaner, B. E. A metallographic and X-ray study of the $\mathrm{UO}_{2}-\mathrm{ZrO}_{2}$ system. $J$. phase diagram in the hyper-stoichiometric region and consequences for the fuel rod liquefaction in oxidising conditions. J. Nucl. Mater. 2008, 375 (3), 397-409. Nucl. Mater. 1963, $9(1), 18-52$. materials from Three Mile Island Unit 2. Nucl. Technol. 1989, 87 (1), 137-145.

(33) Grambow, B.; Poinssot, C. Interactions between nuclear fuel and water at the Fukushima

(34) Pontillon, Y.; Ducros, G.; Malgouyres, P. P. Behaviour of fission products under severe PWR accident conditions VERCORS experimental programme-Part 1: General description of the programme. Nucl. Eng. Des. 2010, 240 (7), 1843-1852. 
(35) Bottomley, P. D. W.; Brémier, S.; Papaioannou, D.; Walker, C. T. EPMA and X-Ray diffraction of the degraded fuel bundle from the Phebus FPT1 test. Microchim. Acta 2002, $139(1-4), 27-38$.

(36) Shiryaev, A. A.; Vlasova, I. E.; Burakov, B. E.; Ogorodnikov, B. I.; Yapaskurt, V. O.; Averin, A. A.; Pakhnevich, A. V.; Zubavichus, Y. V. Physico-chemical properties of Chernobyl lava and their destruction products. Prog. Nucl. Energy 2016, 92, 104-118.

(37) Konings, R. J. M.; Wiss, T.; Beneš, O. Predicting material release during a nuclear reactor accident. Nat. Mater. 2015, 14 (3), 247-252.

(38) Kleykamp, H. The chemical state of the fission products in oxide fuels. J. Nucl. Mater. 1985, $131(2-3), 221-246$.

(39) Pontillon, Y.; Ducros, G. Behaviour of fission products under severe PWR accident conditions. The VERCORS experimental programme-Part 2: Release and transport of fission gases and volatile fission products. Nucl. Eng. Des. 2010, 240 (7), 1853-1866.

(40) Marshall, T. A.; Morris, K.; Law, G. T. W.; Mosselmans, J. F. W.; Bots, P.; Parry, S. A.; Shaw, S. Incorporation and retention of 99-Tc(IV) in magnetite under high $\mathrm{pH}$ conditions. Environ. Sci.Technol. 2014, 48 (20), 11853-11862.

(41) Kobayashi, T.; Scheinost, A. C.; Fellhauer, D.; Gaona, X.; Altmaier, M. Redox behavior of $\mathrm{Tc}(\mathrm{VII}) / \mathrm{Tc}(\mathrm{IV})$ under various reducing conditions in $0.1 \mathrm{M} \mathrm{NaCl}$ solutions. Radiochim. Acta 2013, 101 (5), 323-332.

(42) Lee, M.-S.; Um, W.; Wang, G.; Kruger, A. A.; Lukens, W. W.; Rousseau, R.; Glezakou, V.-A. Impeding ${ }^{99} \mathrm{Tc}(\mathrm{IV})$ mobility in novel waste forms. Nat. Commun. 2016, 7, 12067. 
570

571

572

573

574

575

576

577

578

579

580

581

582

583

584

585

586

587

(43) Burns, P. C.; Ewing, R. C.; Navrotsky, A. Nuclear fuel in a reactor accident. Science 2012, 335 (6073), 1184-1188.

(44) Ferry, C.; Piron, J.-P.; Poulesquen, A.; Poinssot, C. Radionuclides release from the spent fuel under disposal conditions: Re-evaluation of the instant release fraction. MRS Proc. 2008, $1107,447$.

(45) Ewing, R. C. Long-term storage of spent nuclear fuel. Nat. Mater. 2015, 14 (3), 252-257.

(46) Burns, P. C.; Klingensmith, A. L. Uranium mineralogy and neptunium mobility. Elements 2006, 2 (6), 351-356.

(47) Salbu, B.; Janssens, K.; Lind, O. C.; Proost, K.; Gijsels, L.; Danesi, P. R. Oxidation states of uranium in depleted uranium particles from Kuwait. J. Environ. Radioact. 2004, 78 (2), 125-135.

(48) Hellmann, R.; Cotte, S.; Cadel, E.; Malladi, S.; Karlsson, L. S.; Lozano-Perez, S.; Cabié, M.; Seyeux, A. Nanometre-scale evidence for interfacial dissolution-reprecipitation control of silicate glass corrosion. Nat. Mater. 2015, 14 (3), 307-311.

(49) Air Quality Criteria for Particulate Matter Volume II; EPA/600/P-99/002bF, United States Environmental Protection Agency, National Center for Environmental Assessment: NC, 2004. 